\title{
Signaling at the Gliovascular Interface
}

\author{
Marie Simard, Gregory Arcuino, Takahiro Takano, Qing Song Liu, and Maiken Nedergaard \\ Departments of Neurosurgery and Cell Biology, New York Medical College, Valhalla, New York 10590
}

\begin{abstract}
Advances in fluorescent calcium indicating dyes over the past decade have identified calcium signaling as the tool by which astrocytes communicate among themselves and with neighboring neurons. Studies of astrocyte-neuron interactions have shown that calcium signaling is a potent modulator of the strength of both excitatory and inhibitory synapses. The concept that astrocytes possess a mechanism for rapid cell communication has not been incorporated, however, into the supportive functions of astrocytes. Because many of the classical tasks of astrocytes are linked to the blood-brain barrier, we have here examined the expression of proteins required for calcium signaling in their vascular end-foot processes. The gap junction protein, $\mathrm{Cx} 43$, was expressed intensively around the vessels interconnecting astrocytic end-foot processes. These gap junctions permitted diffusion of Lucifer yellow, specifically along the path of glial end feet apposed to the vessel wall. The purinergic receptors, $\mathrm{P} 2 \mathrm{Y}(2)$ and P2Y(4), were also strongly expressed at the gliovascular interface and colocalized with GFAP around larger vessels in cortex. Multiphoton imaging of freshly prepared brain slices loaded with Fluo-4/AM revealed that ATP mobilized cytosolic calcium in astrocytic end feet, whereas electrical stimulation triggered calcium waves propagating along the vessel wall. Brain endothelial cells and pericytes were physically separated from astrocytes by the basal lamina and responded only weakly to ATP. These observations identify astrocytic end-foot processes plastered at the vessel wall as a center for purinergic signaling. It is speculated that calcium signaling may play a role in astrocytic functions related to the blood-brain barrier, including blood flow regulation, metabolic trafficking, and water homeostasis.
\end{abstract}

Key words: calcium; ATP; gap junction; glucose; blood flow; blood- brain barrier

\section{Introduction}

Astrocytes are electrically nonexcitable cells that traditionally have been regarded as the brain's supportive cells. The concept that astrocytic functions were restricted to "housekeeping tasks" was first questioned by the finding that astrocytes actively propagate calcium signals (Cornell-Bell et al., 1990). Stimulation of single astrocytes resulted in expanding waves of intracellular calcium increments, which engaged $>20-100$ neighboring astrocytes in cell cultures (Charles et al., 1991; Smith, 1992). The calcium waves were readily transmitted to neighboring neurons, suggesting that astrocytes may modulate neuronal activity (Nedergaard, 1994; Parpura et al., 1994). In fact, a surge of later studies have shown that astrocytes regulate the strength of synaptic transmission in several different systems, including cocultures (Araque et al., 1998), the intact retina (Newman and Zahs, 1998), and hippocampal slices (Kang et al., 1998), and that Schwann cells are an active component of neuromuscular junctions (Robitaille, 1998). In all of these studies, cytosolic calcium was identified as a critical factor for astrocytic activation and their active participation in the tripartite synapse (Haydon, 2000). The observation that astrocytes possess a mechanism by which they can activate a large number of neighboring astrocytes within a rela-

Received April 9, 2003; revised Aug. 19, 2003; accepted Aug. 20, 2003.

This work was supported by the National Institute of Neurological Disorders and Stroke-National Institutes of Health (NS01672 to William T. Couldwell; NS30007, NS38073, and RR14661 to M.N.). We thank Steve Goldman and Gerry Dienel for comments on this manuscript.

Correspondence should be addressed to Dr. Maiken Nedergaard, Center for Aging and Developmental Biology, University of Rochester School of Medicine, 601 Elmwood Avenue, Rochester, NY 14642. E-mail: nedergaard@urmc.rochester.edu.

Copyright $\odot 2003$ Society for Neuroscience $\quad$ 0270-6474/03/239254-09\$15.00/0 tively short time frame of seconds, however, has not been incorporated into the classic functions of astrocytes. For example, it is not known whether astrocytic calcium signaling modulates metabolic trafficking across the blood-brain barrier (BBB) or plays a role in local regulation of blood flow. Because many of the functions of astrocytes are related to their structural organization around the blood-brain barrier (del Zoppo and Hallenbeck, 2000), we have here asked to what extent vascular end feet are equipped for the generation of calcium waves. Recent in vitro work has pointed to a central role of both purinergic receptors and the gap junction protein, $\mathrm{Cx} 43$, in the generation and propagation of astrocytic calcium waves (Cotrina et al., 1998; Guthrie et al., 1999; Arcuino et al., 2002). We observed that purinergic receptors are intensively expressed by astrocytes, particularly at their end feet. Surprisingly, Cx43 expression was also concentrated around large and medium-size vessels and linked individual astrocytic end-foot processes into a continuous sheet lining the vessel wall. Multiphoton confocal imaging of acutely prepared brain slices loaded with the calcium indicator, Fluo-4/AM, revealed that the astrocytic vascular end feet responded to local application of ATP and propagated calcium waves after focal electrical stimulation. These observations suggest that astrocytic calcium signaling, which has been implicated previously in astrocyte-neuronal communication, also is expressed at the gliovascular interface. As such, it is possible that calcium signaling plays a regulatory role in the supportive functions of astrocytes, including local blood flow regulation and metabolic trafficking.

\section{Materials and Methods}

Immunohistochemistry. Young male Sprague Dawley rats weighing 150 $175 \mathrm{mg}$ (8-10 weeks) were deeply anesthetized with an intraperitoneal 
injection of pentobarbital (40 mg/kg body weight). The rats were positioned at a $15^{\circ}$ upright angle, and intracardiac perfusion was performed using a 21 gauge Teflon catheter inserted into the aorta via the left ventricle. A perfusion of $500 \mathrm{ml}$ of PBS (Sigma, St. Louis, MO) with $2 \mathrm{ml} / \mathrm{l}$ heparin (5000 U/cc heparin solution) was administered via a Master flex pump controller with a $0.8 \mathrm{~mm}$ tube at a slow rate $(0.3 \mathrm{ml} / \mathrm{min})$. The tissues were then fixed in situ by perfusion of 11 of PBS containing $4 \%$ paraformaldehyde administered at a rate increasing up to $7 \mathrm{ml} / \mathrm{min}$ over a $1 \mathrm{hr}$ period. The brain was removed and postfixed in $4 \%$ paraformaldehyde for a period of $4 \mathrm{hr}$ with ensuing washes in PBS. Vibratome (TPI, St. Louis, MO) sections of $100-150 \mu \mathrm{m}$ were prepared and immersed in PBS at $4^{\circ} \mathrm{C}$.

The rat brain sections were individually placed in 24-well culture dishes and gently washed several times in $0.1 \mathrm{M}$ PBS. The sections were permeabilized and blocked with a solution of $1 \%$ L-lysine monohydrochloride (Sigma) in $0.1 \mathrm{~m} \mathrm{PBS}$ and $100 \mu \mathrm{l}$ Triton X-100 for $24 \mathrm{hr}$ at $4^{\circ} \mathrm{C}$. Tissue sections were then incubated in a solution of primary antibody diluted in the permeabilizing-blocking agent for a period of $72 \mathrm{hr}$ : a monoclonal antibody against GFAP (G3893, 1:100; Sigma); a polyclonal antibody against aquaporin 4 (AQP-4) (AB3068, 1:100; Chemicon International, Temecula, CA); a polyclonal antibody against Cx43 (71-0700, 1:500; Zymed Laboratories, San Francisco, CA); polyclonal antibodies against P2Y2 receptor and P2Y4 receptor (APR010 and APR006, 1:50 for both antibodies; Alomone Labs, Jerusalem, Israel); a monoclonal antibody against rat endothelial cell antigen (RECA)-1 antigen (MCA970, 1:100; Serotec, Raleigh, NC); a polyclonal antibody against laminin (L9393, 1:75; Sigma); a monoclonal antibody against desmin (M0760, 1:100; Dako, Carpinteria, CA); and a monoclonal antibody against smooth muscle actin (128M, 1:75; BioGenex, San Ramon, CA). After several washes in $0.1 \mathrm{M}$ PBS, the secondary antibodies Cy3-goat antirabbit (111-165-003; Jackson ImmunoResearch, West Grove, PA) and FITC-goat anti-mouse (F0257, Sigma) were applied at dilutions of 1:100 and 1:200, respectively, for a period of $48 \mathrm{hr}$. The reactions were completed by washing with $0.1 \mathrm{M}$ PBS several times and mounting the sections on glass slides in Slow Fade (Molecular Probes, Eugene, OR). Immunofluorescence was visualized using a Bio-Rad MRC1000 confocal scanning microscope attached to an inverted microscope (IX81, Olympus, Tokyo, Japan).

Slice preparation. Cortical slices from juvenile rats [postnatal day 15 (P15)] were prepared as described previously (Kang et al., 1998; Kang and Nedergaard, 2000). In brief, the slices were submerged in gassed $\left(95 \% \mathrm{O}_{2}\right.$ and $\left.5 \% \mathrm{CO}_{2}\right)$ ice-cold cutting solution, and 300- $\mu$ m-thick slices were cut on a Vibratome (TPI). The cutting solution contained (in mu): $2.5 \mathrm{KCl}, 1.25 \mathrm{NaH}_{2} \mathrm{PO}_{4}, 10 \mathrm{MgSO}_{4}, 5 \mathrm{CaCl}_{2}, 10$ glucose, 26 $\mathrm{NaHCO}_{3}$, and 230 sucrose. Slices were incubated for $1 \mathrm{hr}$ in artificial CSF (aCSF) and then loaded with Fluo-4/AM $(10 \mu \mathrm{M})$ for $1.5 \mathrm{hr}$ in aCSF containing $0.05 \%(\mathrm{w} / \mathrm{v})$ Pluronic F-127 (in micrometers), and gassed with $5 \% \mathrm{CO}_{2}$ and $95 \% \mathrm{O}_{2}$ at $35^{\circ} \mathrm{C}$. In selected experiments, Texas Red Dextran $(40,000 \mathrm{kDa} ; 1 \mathrm{~mm} ; 300 \mu \mathrm{l})$ was injected intracardially, immediately before preparation of brain slices, to outline the vasculature (Morris et al., 1999; Zhang et al., 1999). The slices were transferred to a recording chamber $(1.5 \mathrm{ml})$ that was perfused continuously with aCSF. The aCSF contained (in mM): $126 \mathrm{NaCl}, 2.5 \mathrm{KCl}, 1.25 \mathrm{NaH}_{2} \mathrm{PO}_{4}, 2$ $\mathrm{MgCl}_{2}, 2 \mathrm{CaCl}_{2}, 10$ glucose, and $26 \mathrm{NaHCO}_{3}, \mathrm{pH} 7.4$, when gassed with $95 \% \mathrm{O}_{2}$ and $5 \% \mathrm{CO}_{2}$. Whole-cell recordings were obtained by using a Multiclamp amplifier (Axon Instruments, Foster City, CA). Recording electrodes with resistances of 3-7 $\Omega$ were pulled from KG-33 glass capillaries, using a P-97 micropipette puller (Sutter Instrument, Novato, CA). The intracellular solution contained (in $\mathrm{mm}$ ): $140 \mathrm{KCl}, 2 \mathrm{MgCl}_{2}, 10$ EGTA, 10 HEPES, pH 7.2 with $\mathrm{KOH}$. Lucifer yellow $\mathrm{CH}(2 \mathrm{mg} / \mathrm{ml}$; delithium salt, Sigma L-0259) was added into the solution before recording, and the solution was heated to $50-60^{\circ} \mathrm{C}$ to facilitate the dissolvability of Lucifer yellow.

Astrocytes were distinguished by small, round cell bodies $(<10 \mu \mathrm{m})$ without visible processes under a differential interference contrast (DIC) microscope, a high resting membrane potential $(\sim 80 \mathrm{mV})$, small input resistance $<20 \mathrm{M} \Omega$ ), and the failure of depolarizing voltage steps to evoke action potentials. ATP was applied locally by use of patch pipette filled with $100 \mu \mathrm{M}$ ATP in the recoding solution, $\mathrm{pH}$ 7.3. ATP was deliv- ered by a Picrospitzer (General Valve, Fairfield, NJ) using a $1 \mathrm{sec}$ puff with 3-4 psi air pressure. Focal electrical stimulation $(2 \mathrm{sec}, 100 \mathrm{~Hz}$ pulse at $100 \mu \mathrm{A}$ ) was delivered by bipolar electrodes (World Precision Instruments) placed on the surface of the slice.

Multiphoton laser scanning microscopy imaging. A Mai Tai laser (SpectraPhysics, Inc.) attached to a confocal scanning system (Fluoview, Olympus) and an upright microscope (IX81W, Olympus) were used for calcium imaging experiments. The calcium indicator, Fluo-4/AM (10 $\mu \mathrm{M}, 1.5 \mathrm{hr}$ ), was excited at $800 \mathrm{~nm}$, and emission was collected at $530-$ $580 \mathrm{~nm}$. Three serial optical sections, each with a distance of $5 \mu \mathrm{m}$, were collected every $1.5 \mathrm{sec}$. The serial optical sections were superimposed to visualize more cells in the same field. After recordings, the slides were fixed in $4 \%$ paraformaldehyde for $48 \mathrm{hr}$ and processed for immunohistochemistry as described above. Texas Red Dextran was excited at 860 $\mathrm{nm}$, and emission was collected at 575-645 $\mathrm{nm}$. Lucifer yellow was excited at $850 \mathrm{~nm}$, and emission was collected at 575-645 nm.

\section{Results}

\section{The polarized phenotype of astrocytes in situ}

Astrocytes are routinely identified by their immunoreactivity against GFAP, an intermediate filament expressed exclusively by astrocytes in brain. GFAP labeling of vibratome slices prepared from adult rats showed that astrocytes were evenly distributed across cortex, each covering a territory of $\sim 30-80 \mu \mathrm{m}$ (Fig. $1 \mathrm{~A}$ ). Individual astrocytes were star shaped, with multiple branching processes, when visualized by a monoclonal GFAP antibody. The gradual thinning of the processes, combined with sparse contact with neighboring astrocytes, gave rise to a highly symmetrical organization, in which each astrocyte created its own domain, as described originally by Ellisman and coworkers (Bushong et al., 2002). The exception to this orderly distribution was that most, if not all, astrocytes extended one or several processes to nearby vessels. The GFAP+ vascular processes were often of a wide diameter. The tips of the vascular processes abutted into contiguous end feet, which were plastered along the vessel wall (Fig. $1 \mathrm{~A}$ ). The end feet were rounded or elongated with a mean diameter of $4-8 \mu \mathrm{m}$. GFAP was organized into two distinct patterns within the individual end feet. Some end feet contained GFAP in a spiral or wagon wheel configuration (Fig. $1 C, D$ ), whereas GFAP in other end feet was organized in a parallel array of circumferential fibers surrounding the vessel (Fig. 1E,F). These were notable for their alignment perpendicular to the linear vector of the vessel.

GFAP + processes did not systematically cover smaller vessels and capillaries. Occasional GFAP + processes made contact with the walls of small vessels and capillaries. GFAP does not define the cytoplasmic outline of astrocytes (Bushong et al., 2002), and the full coverage of the vasculature by astrocytes was visualized by labeling astrocytes against aquaporin-4, a member of the water channel family expressed exclusively by astrocytes in brain (Nielsen et al., 1997; Rash and Yasumura, 1999). Aquaporin-4 expression outlined the entire network of vessels, demonstrating that astrocytic end feet, albeit GFAP negative, completely cover the cerebral vasculature (Fig. $1 B$ ).

We next quantified the extent of GFAP expression of astrocytic end feet plastered at the vessel wall. Vibratome sections were double labeled against laminin (polyclonal) and GFAP (monoclonal). The vessel area was defined by selecting areas labeled against laminin with a fluorescence emission $>10$-fold higher than baseline fluorescent using a $20 \times$ oil lens (Fig. $2 A$ ). The percentage of GFAP staining ( $>10$-fold baseline emission) (Fig. $2 B, C$ ) within the area selected as laminin + was quantified using Metamorph (Universal Imaging, West Chester, PA). On the basis of laminin labeling, the vessels were categorized into three groups: large $(>16 \mu \mathrm{m})$, medium $(8-16 \mu \mathrm{m})$, and small $(<8$ 

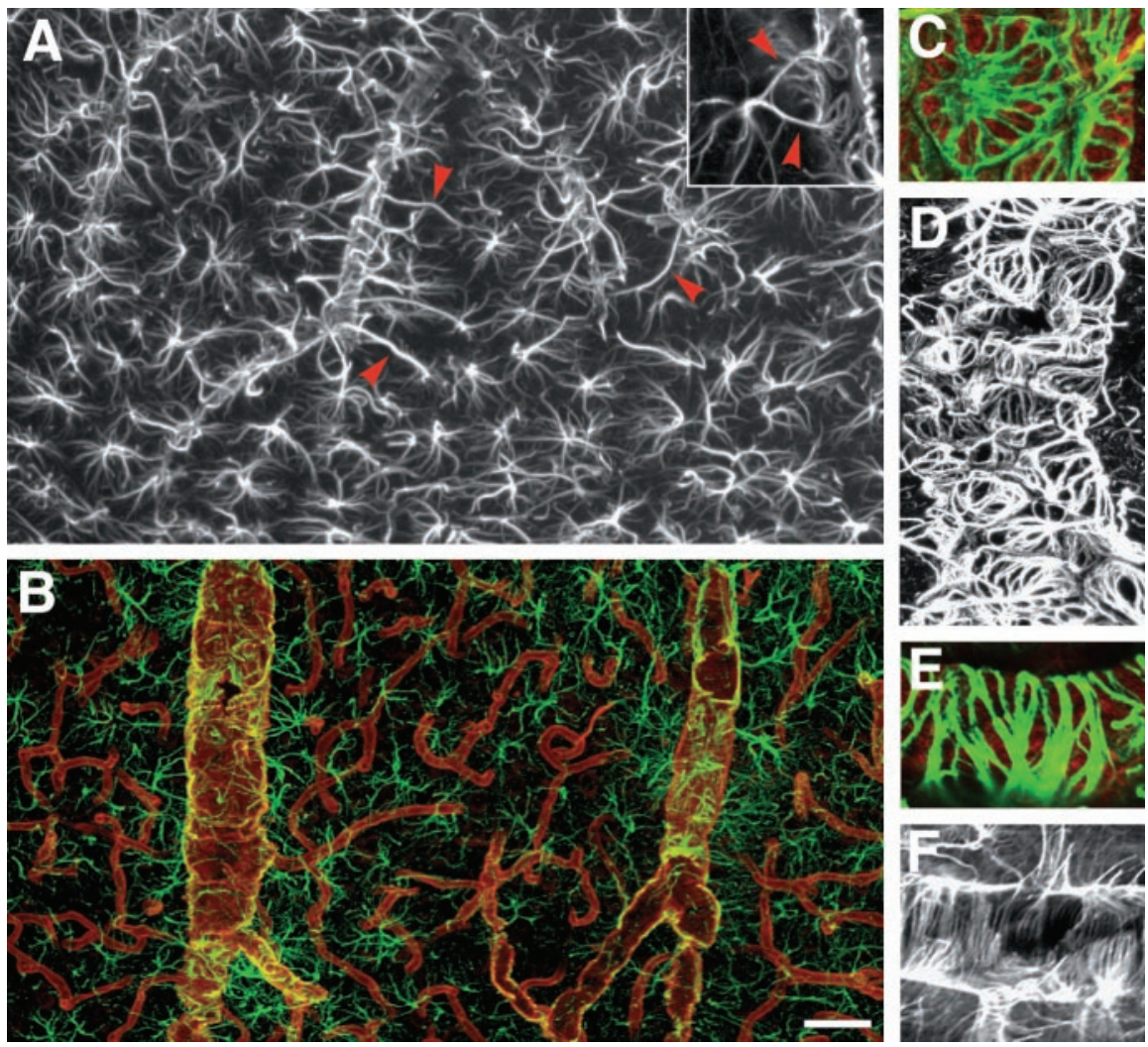

Figure 1. Not all vascular astrocytic end-foot processes are GFAP positive. A, GFAP immunolabeling of astrocytes in cortex Individual astrocytes are star-shaped and distributed symmetrically, with minimal contact with neighboring astrocytes. Vascular processes differ from other processes by being straight, unbranched, and of wide diameter (red arrowheads). The surfaces of large to medium-size vessels were densely covered by GFAP + astrocytic end feet. Inset, An astrocyte with two vascular processes. $B$, Double immunolabeling of AQP-4 (red) and GFAP (green). Aquaporin-4 immunolabeling reveals that the entire network of vessels, including capillaries, is covered by astrocytic processes, albeit GFAP negative. Smaller vessels and capillaries are mostly GFAP negative but display intense labeling against the astrocyte-specific channel AQP-4. The AQP-4 labeling reveals continuous coverage by astrocytic end feet. $C-F$, Examples of organization of GFAP in astrocytic end feet around larger vessels. Cand $D$ display examples of wagon-wheel or rosette formation of GFAP filaments in the vascular end feet, whereas $E$ and $F$ are examples on parallel arrays running perpendicular to the length of the vessel. C and $E$ are double labeled against GFAP (green) and AQP-4 (red), whereas $D$ and $F$ are stained against GFAP only. Scale bar: inset, $40 \mu \mathrm{m} ; A, 10 \mu \mathrm{m} ; B, 60 \mu \mathrm{m} ; C, E, 5 \mu \mathrm{m} ; D, F, 30 \mu \mathrm{m}$.

around larger vessels and appeared to physically link astrocytic end feet in a continuous sheet plastered around the vessel wall (Fig. $3 B, C$ ). In contrast, $\mathrm{Cx} 43$ immunoreactive punctation was not observed in endothelial cells (Fig. $3 F$ ). Endothelial cells were identified either by an antibody directed against RECA (Fig. $3 F$ ) (Duijvestijn et al., 1992) or by labeling against the glucose transporter, GLU-1 (data not shown) (Simpson et al., 2001). In either case, Cx43-positive plaques were localized outside the endothelial cells. Endothelial cells in peripheral tissue express $\mathrm{Cx} 43$ in regions that experience turbulent shear stress from disturbed blood flow or in response to mechanical stress or injury (Gabriels and Paul, 1998; Hong and Hill, 1998), but such a pattern of expression was not observed in brain. Meninges also displayed abundant expression of $\mathrm{Cx} 43$ in accordance with earlier reports (Fig. $3 D, E$ ) (Grafstein et al., 2000).

To establish whether gap junctions interconnecting astrocytic end feet are functional, we next used multiphoton laser scanning microscopy microscopy to analyze the diffusion of Lucifer yellow [molecular weight (MW) 443] in freshly prepared cortical slices. Acute slices were prepared from $\mathrm{P} 15$ rat pups, and astrocytes close to the vasculature, often with an end-foot process visible under DIC optics, were filled with Lucifer yellow by a patch pipette (Fig. 4). The failure to fire action potentials of the Lucifer yellow-filled cell in Figure $3 A$ and the low input resistance are typical for astrocytes. In 8 of 20 experiments, Lucifer yellow diffused from end foot to end foot along the vessel wall, demonstrating

$\mu \mathrm{m})$. The analysis revealed that larger and medium-size vessels were mostly covered by GFAP+ astrocytic processes, whereas GFAP labeling surrounding small vessels did not differ significantly from the percentage of GFAP labeling outside the vasculature (non-vessel) (Fig. 2D). A similar pattern of GFAP-positive astrocytic processes apposed to larger vessels and GFAP-negative processes around small vessels was noted in hippocampal slices.

\section{Gap junction plaques link astrocytic end feet}

Cx43 is recognized as the primary astrocytic gap junction protein (Dermietzel et al., 1991; Giaume et al., 1991). In cultured astrocytes, $\mathrm{Cx} 43$ organizes into gap junction plaques that are distributed evenly in areas of cell-cell contact. In the cortex of adult rats, we found that $\mathrm{Cx} 43$ immunoreactivity was intensively present around large and medium-size vessels (Fig. 3A) (Yamamoto et al., 1990). In general, the Cx43 immunoreactive plaques surrounding vessels were large, $\sim 2-5 \mu \mathrm{m}$ in diameter, and often organized in a "spider web-like" pattern around the vessels, delineating the areas of contact between the contiguous end feet (Fig. $3 A, B$ ). Within the brain parenchyma, e.g., outside the vessel wall, $\mathrm{Cx} 43$ immunoreactivity was evenly distributed in smaller plaques $(<1 \mu \mathrm{m})$ lacking an apparent pattern of organization. Cx43-positive plaques were strictly colocalized with GFAP that the Cx43-immunoreactive plaques depicted in Figure 3 are functional, e.g., allowing free exchange of a gap junctionpermeable indicator. Similar observations originally reported in Zahs and Newman (1997) demonstrated extensive diffusion of Neurobiotin between astrocytes. Combined, these studies suggest that the vascular end feet are interconnected by an extensive array of open gap junctions and that this coupling may allow the end feet to act as a functional unit.

\section{Purinergic P2Y receptors preferentially expressed by astrocytic end feet}

Several lines of recent studies have identified nucleotides and purinergic signaling as key mediators of astrocytic calcium waves in cultures (Cotrina et al., 1998; Guthrie et al., 1999; Arcuino et al., 2002). Astrocytes express P2Y(1), P2Y(2), P2Y(4), and the ionotropic P2X(7) receptor in cultures (John et al., 1999; Jimenez et al., 2000), as well as acutely isolated from rat hippocampus (Zhu and Kimelberg, 2001). Surprisingly, we found that most immunoreactivity against both the $\mathrm{P} 2 \mathrm{Y}(2)$ and $\mathrm{P} 2 \mathrm{Y}(4)$ receptors was colocalized with GFAP in perivascular astrocytes (Figs. 5, 6). The P2Y(2) and P2Y(4) labeling was intense around large and medium-size vessels, but small capillary size vessels were also immunoreactive (Figs. 5, 6). Minimal P2Y(2) and P2Y(4) immu- 

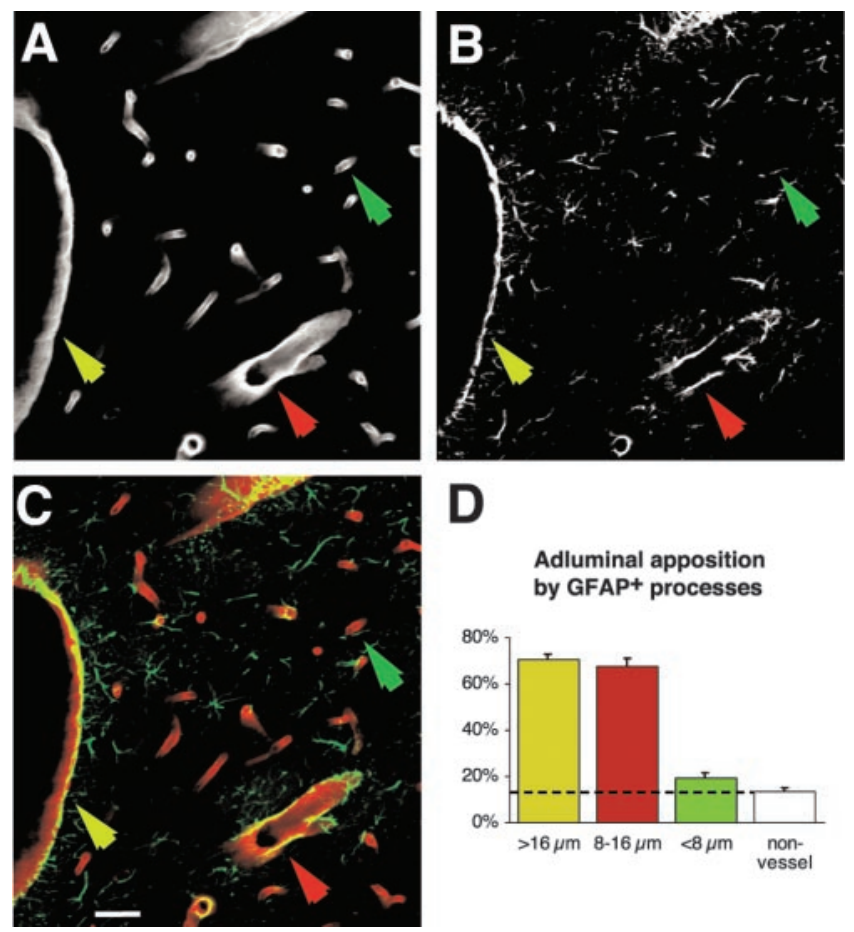

D

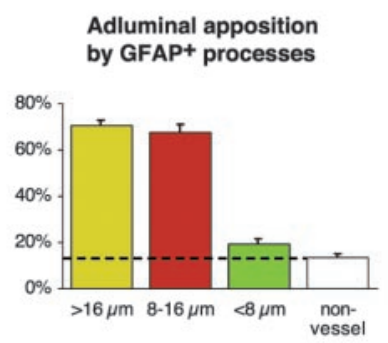

Figure 2. Quantification of GFAP expression in astrocytic end feet plastered at the vessel wall. $A-C$, Double immunostaining against laminin $(A)$ and GFAP $(B)$ and overlay ( () of laminin (red) and GFAP (green) in cortex. Scale bar, $20 \mu \mathrm{m}$. D, Quantification of GFAP expression along the vasculature as a function of the vessel size. Approximately $70 \%$ of the vessel wall of larger ( $>16 \mu \mathrm{m}$; yellow arrow) and medium-size $(8-16 \mu \mathrm{m}$; red arrow) vessels were covered by GFAP + astrocytic end feet. In contrast, only $19 \pm 2 \%$ of astrocytic processes in contact with small vessels $(<8 \mu \mathrm{m}$; green arrow) were GFAP + . This percentage of GFAP expression around small vessels did not differ significantly from the percentage of GFAP expression outside the vessel wall ( $13 \pm 2 \%$ non-vessel; $p=0.33$; unpaired $t$ test). ${ }^{*} p<0.0001$; unpaired $t$ test; $n=$ 10 slices.

noreactivity was evident outside the vessels, and endothelial cells were not immunoreactive, e.g., did not express $\mathrm{P} 2 \mathrm{Y}(2)$ or $\mathrm{P} 2 \mathrm{Y}(4)$ receptors (Figs. $4 C, E, 5 D, E$ ). Thus, the overall distribution of immunoreactivity against $\mathrm{P} 2 \mathrm{Y}(2)$ and $\mathrm{P} 2 \mathrm{Y}(4)$ was similar to Cx43-positive plaques, e.g., numerous intensely stained puncta of large size surrounded vessels, whereas smaller and weaker stained puncta were scattered outside the vessels. Unlike the spider web pattern of $\mathrm{Cx} 43$ expression, however, the $\mathrm{P} 2 \mathrm{Y} 2$ and $\mathrm{P} 2 \mathrm{Y} 4$ receptors appear diffusely distributed throughout the end-foot surface membrane. P2Y(1) immunoreactivity was weak in adult rat brain, consistent with the observation that $\mathrm{P} 2 \mathrm{Y}(1)$ expression is downregulated during development (data not shown) (Zhu and Kimelberg, 2001). A commercial antibody directed against $\mathrm{P} 2 \mathrm{X}(7)$ receptors gave rise to an inconsistent and unspecific pattern of staining (data not shown).

The basal lamina separates astrocytes, endothelial cells, and pericytes

The basal lamina is a membrane composed of type IV collagen, fibronectin, and laminin interposed between endothelial cells and astrocytic end feet (Fig. 7 A,B) (del Zoppo and Hallenbeck, 2000). Using a polyclonal antibody directed against laminin, it was noted that the basal lamina was composed of two membranes. A thick intensively stained membrane faced the astrocytic foot processes, whereas a thinner membrane faced the endothelial cell layer. Characteristically, the inner membrane contained
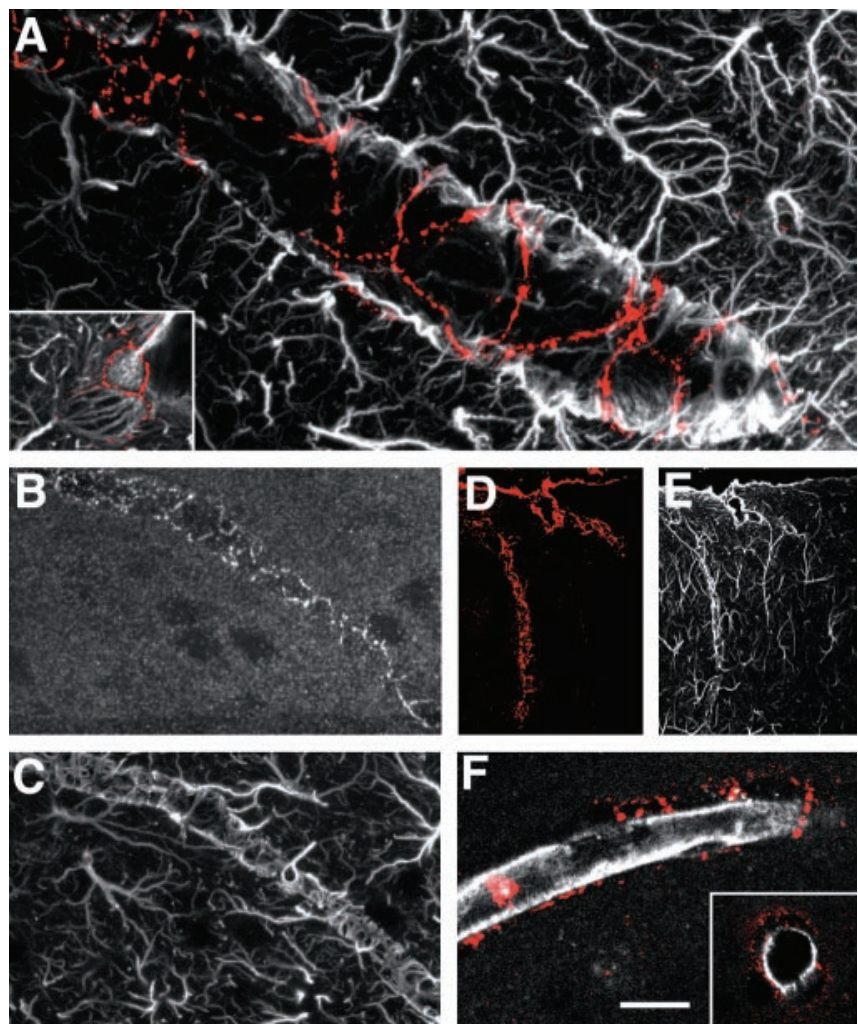

Figure 3. Cx43 gap junction plaques are localized primarily around vessels and connect the end feet of astrocytes. A, Double immunolabeling against GFAP (white) and Cx43 (red). C x43immunoreactive plaques formed a spider web pattern around a medium-size vessel. Inset, High-power image illustrating the distribution of $\mathrm{C} 433$-immunoreactive plaques around an astrocytic foot process. $B, C$, Double immunolabeling against $C x 43(B)$ and GFAP. Large $C \times 43-$ immunoreactive plaques interconnect astrocytic GFAP-positive end feet. $D, E$, Intense $C \times 43$ immunoreactivity in pia and penetrating vessels in cortex; labeling against $C \times 43(D$, red) and $\operatorname{GFAP}(E$, white). $F$, Cx43 immunolabeling (red) does not colocalize with an endothelial cell marker, rat endothelial cell antigen (RECA; white); rather, $\mathrm{Cx} 43$ is localized outside the RECApositive cells, consistent with the coexpression of $\mathrm{C} \times 43$ and GFAP in astrocytes. Scale bar: inset, $15 \mu \mathrm{m} ; A, 4 \mu \mathrm{m} ; B, C, 50 \mu \mathrm{m} ; D, E, 120 \mu \mathrm{m} ; F, 40 \mu \mathrm{m}$.

"pockets," frequently in the shape of tunnels running perpendicular to the length of the vessel (Fig. 7A, arrows). The two membranes were often separated, likely an artifact produced during the slide preparation, suggesting that the membranes were only loosely attached to each other. The pockets of the inner membrane of the basal lamina contained desmin-positive pericytessmooth muscle cells (Fig. 7C) (Diaz-Flores et al., 1991; Nakano et al., 2000). The pericytes are elongated cells forming a fibrous network surrounding larger vessels (Fig. 7D). An antibody directed against smooth muscle $\alpha$-actin outlined with high specificity the localization of pericytes-smooth muscle cells (Fig. 7E). Most of the desmin or smooth muscle $\alpha$-actin-positive cells were localized around the major vessels and observed only infrequently in capillaries. Pericytes-smooth muscle cells were embedded in the inner membrane of basal lamina and thereby separated from the endothelial cell layer, whereas both layers of the basal lamina separated endothelial cells from astrocytes. The result was that all three cell types in the blood-brain barrier (endothelial cells, pericytes, and astrocytes) were physically separated from each other. Thus, it is unlikely that a heterotypic gap junction between different cells types can be established within the blood-brain barrier. 
A
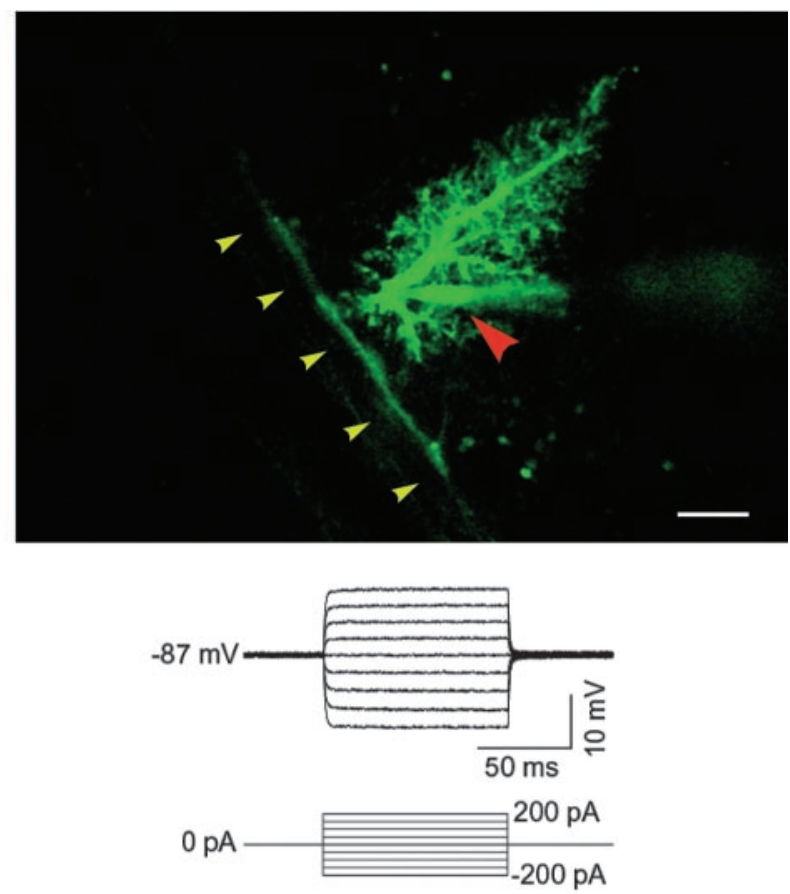

\section{B}

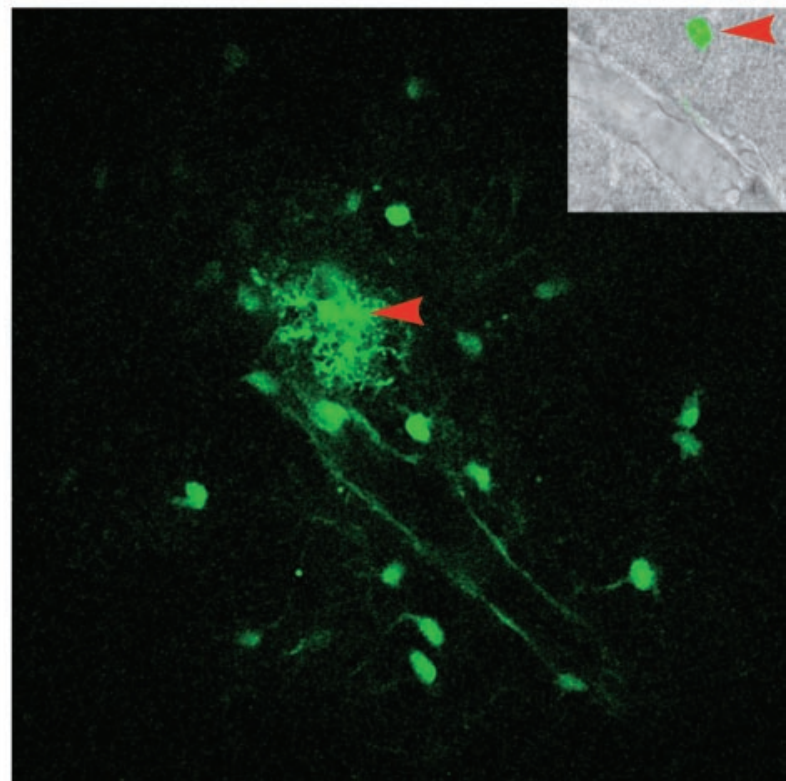

Figure 4. Functional coupling of astrocytic end feet visualized by diffusion of Lucifer yellow. $A$, An astrocyte filled with the gap junction-permeable indicator Lucifer yellow in a freshly prepared cortical slice. Lucifer yellow diffused preferentially along the vessel wall. Red arrowhead indicates Lucifer yellow-filled pipette; yellow arrowheads indicate vessel wall. Current injection failed to evoke action potentials (bottom panel). $B$, Another example of intercellular diffusion of Lucifer yellow along the vessel wall. An astrocyte was filled with Lucifer yellow by a patch electrode (red arrowhead), resulting in extensive intercellular diffusion into neighboring astrocytes and an outlining of their processes plastered around a vessel. Inset, After multiphoton imaging, the slice was fixed and visualized under DIC optics and fluorescence microscopy to depict the position of the Lucifer yellow-filled astrocyte (red arrow-head) in relation to the vessel (yellow arrowhead).

\section{Astrocytes respond in a coordinated pattern to purinergic agonists}

To establish whether the purinergic receptors identified in the gliovascular interface were functional, we next loaded freshly prepared cortical slices (P15) with the calcium indicator Fluo-4/AM
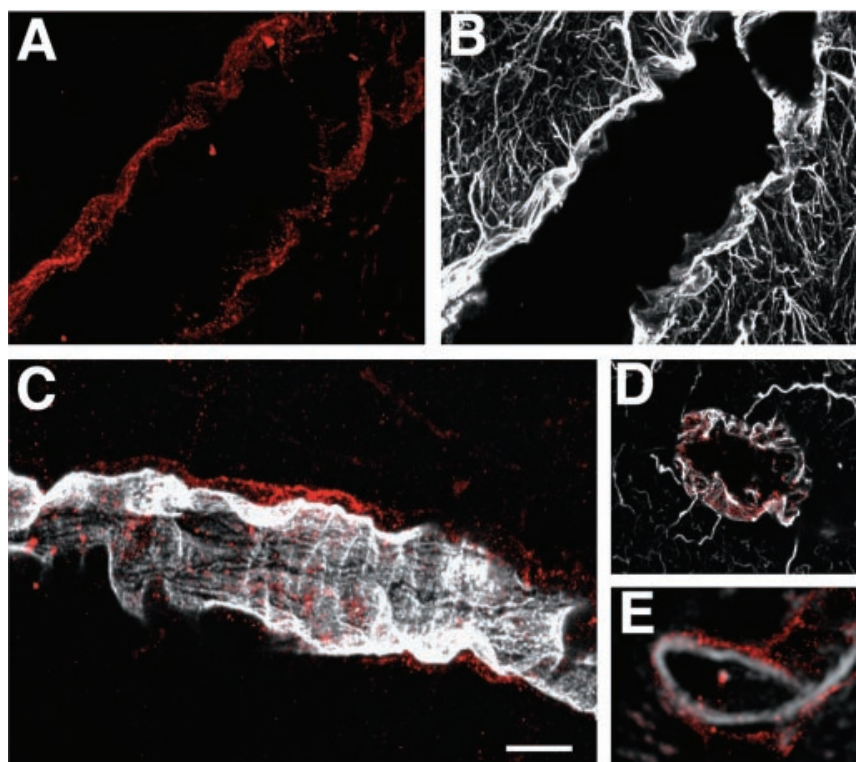

Figure 5. $\quad P 2 Y(2)$ is expressed at the gliovascular interface by astrocytic end feet. $A, B, P 2 Y(2)$ immunoreactivity around a large vessel $(A$, red) and GFAP expression in the same field $(B$, white). C, Double immunoreactivity against P2Y(2) (red) and RECA (white). P2Y immunoreactivity is localized around the RECA-positive endothelial cells. D, Cross section of a GFAP-positive vessel counterstained against $P 2 Y(2)$ receptors showing colocalization (red). E, In comparison, P2Y(2) expression (red) is localized outside the endothelial cell layer (RECA; white) in another cross section. Scale bar: $A, B, 20 \mu \mathrm{m} ; C, 35 \mu \mathrm{m} ; D, E, 40 \mu \mathrm{m}$.

and visualized dynamic changes in cytosolic calcium using multiphoton excitation $(800 \mathrm{~nm})$. Astrocytes preferentially load with calcium indicators in slices prepared from rats older than P10 (Kang et al., 1998; Kang and Nedergaard, 2000), and with multiphoton excitation it was possible to image intact vessels localized $60-120 \mu \mathrm{m}$ below the surface.

To identify the vessels, Texas Red Dextran (MW $200 \mathrm{kDa}$ ) was injected intracardially immediately before preparation of brain slices (Morris et al., 1999; Zhang et al., 1999). The Texas Red Dextran clearly outlined the entire network of vessels and at 860 $\mathrm{nm}$ excitation could be separated from the Fluo-4/AM signal by use of appropriate emission bandpass filters (see Materials and Methods).

During resting conditions, astrocytes displayed low and stable levels of cytosolic calcium (Fig. $8 \mathrm{~B}$ ). After local puffing of ATP $(100 \mu \mathrm{M})$ in the presence of TTX $(1 \mu \mathrm{M})$, robust increases in cytosolic calcium levels were observed. Characteristically, both the astrocytic cell bodies and their vascular processes responded to ATP. Frequently, the vascular processes first became visible after addition of ATP, because of their low baseline levels of calcium. The increase in cytosolic calcium concentrations in the astrocytic end-foot processes was uniform, and it was not possible to distinguish the individual processes from each other (Fig. $8 B)$. Cytosolic calcium levels remained high in the end feet plastered at the vessel wall for several minutes after washout of the ATP. In contrast, calcium levels normalized faster in the astrocytic cell body, resulting in long-lasting outlining of the vasculature by the astrocyte foot processes with high calcium. Labeling against GFAP positively identified almost all cells responding to ATP as astrocytes (Fig. 8A).

Electrical field stimulation was next used to analyze whether astrocytes can support the propagation of calcium waves in situ (Fig. 8C). Stimulation of astrocytic calcium signaling by electrical field stimulation in the presence of TTX resulted in calcium 

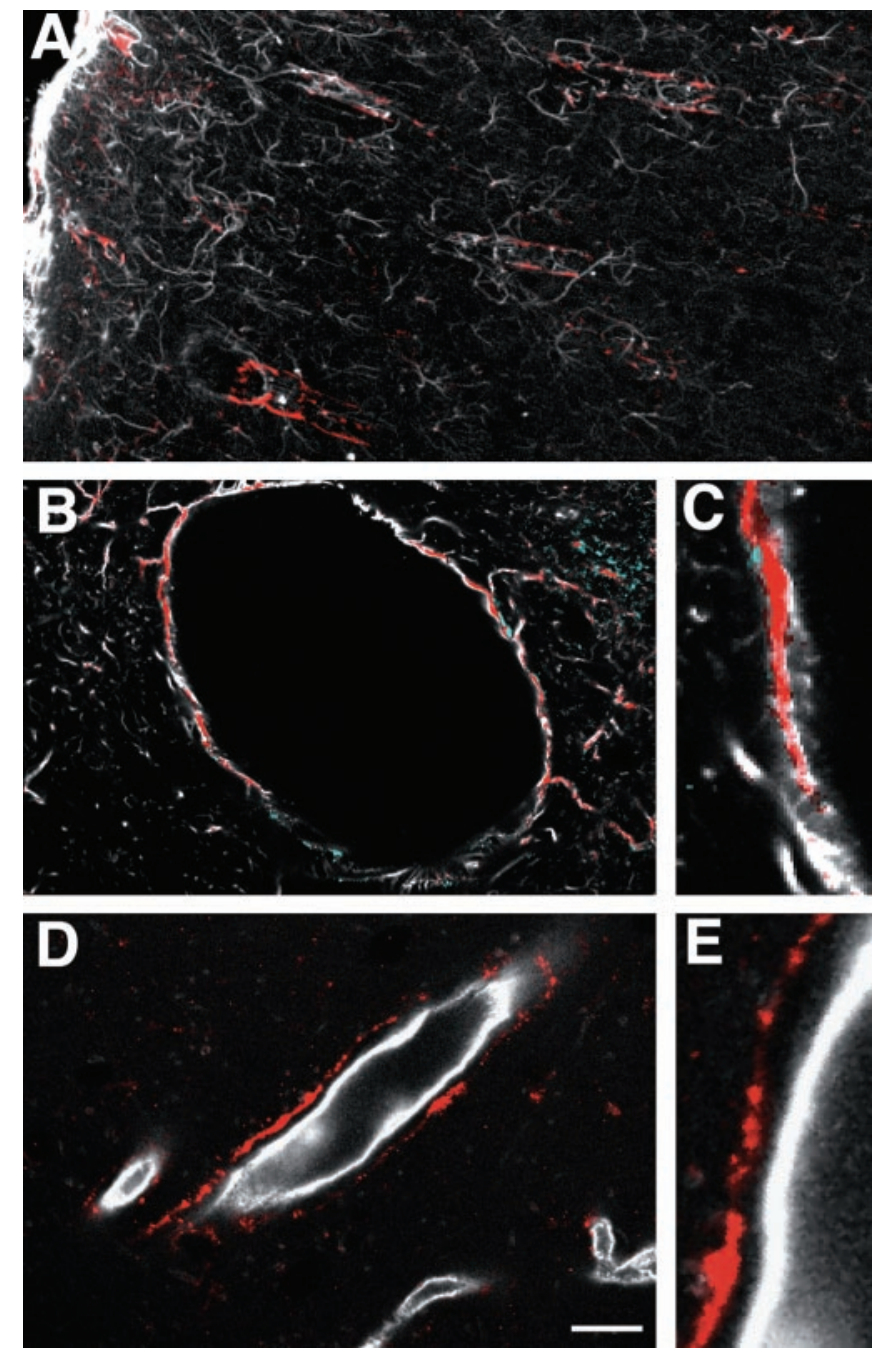

Figure 6. P2Y(4) immunolabeling is strongly coexpressed with GFAP in astrocytic processes. $A$, Double immunolabeling against P2Y(4) (red) and GFAP (white) in cortex. Penetrating larger GFAP + vessels display intense labeling against the P2Y(4) receptor. $B$, Transverse section of larger vessels displaying colocalization of the P2Y(4) receptors and GFAP. C, High magnification of B. D, E, Double immunolabeling against P2Y(4) and RECA. The P2Y(4) immunolabeling is localized outside the endothelial cell layer consistent with its expression in astrocytes. Scale bar: $A, 100 \mu \mathrm{m} ; B, 15 \mu \mathrm{m} ; C, E, 10 \mu \mathrm{m} ; D, 30 \mu \mathrm{m}$.

waves, which often clearly migrated along the vascular end feet plastered at the vessel wall. In a total of 63 experiments using electrical stimulation, we found that 37 (58\%) of the waves propagated along the vessel wall. Propagation along the vessel wall was defined as sequential calcium increases, which migrated a minimal distance of $60 \mu \mathrm{m}$ along the linear vector of the vessel.

Combined, these observations demonstrate that purinergic receptors on astrocytes are functional, that their activation results in a marked and long-lasting mobilization of cytosolic calcium, and that electrical stimulation can trigger calcium waves that sequentially engage astrocytes in acute slice.

\section{Discussion}

The key finding of this study is that the proteins known to be essential for intercellular calcium signaling are expressed predominantly by perivascular astrocytic end feet facing the vessel wall. Specifically, the purinergic receptors $\mathrm{P} 2 \mathrm{Y}(2)$ and $\mathrm{P} 2 \mathrm{Y}(4)$ and gap junctions composed of $\mathrm{Cx} 43$ were abundantly present in astrocytic end feet (Figs. 3, 5, 6). ATP potently mobilized in-
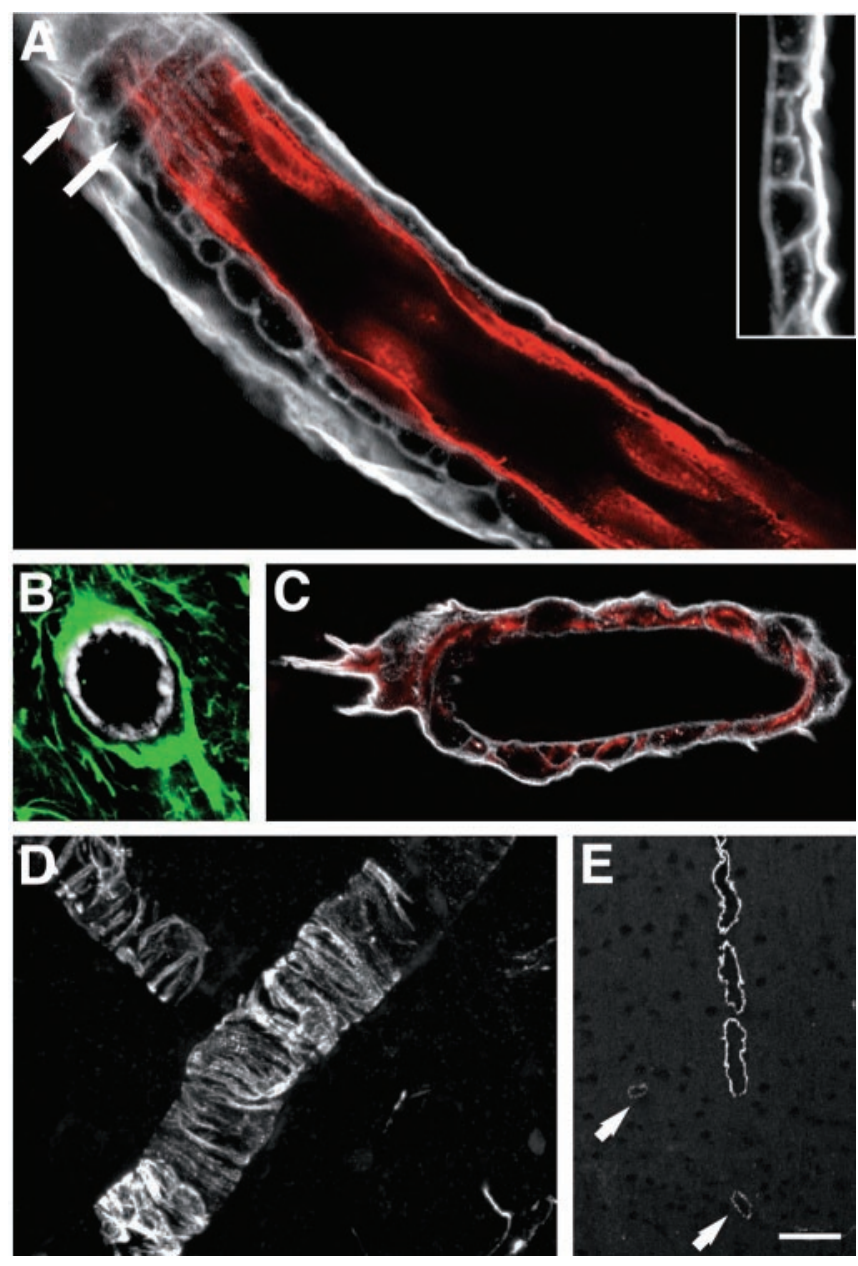

Figure 7. The basal lamina physically separates all three cell types of the blood-brain barrier. $A$, Double immunolabeling against laminin (white) and RECA (red) of a large cortical vessel. The basal lamina consists of an outer thick lamina intensively immunoreactive for laminin and an inner lamina that displays weaker staining for laminin. The inner lamina contains pockets, which often are shaped as tunnels running perpendicular to the length of the vessel (white arrows). Inset, High-power image of a laminin-stained vessel wall illustrating the two laminas. $B$, Large vessel stained against laminin (white) and GFAP (green). GFAP-positive astrocytic end feet cover the basal lamina. C, Desmin-positive pericytes (red) are localized in pockets of the basal lamina (laminin; white). D, High-power view of desmin-positive pericytes. E, An antibody directed against actin smooth muscle (pericyte specific) demonstrates that only large vessels are surrounded by pericytes. Pericytes are absent from the capillary wall, and only weak expression is observed in medium-size vessels (white arrows). Scale bar: $A, 20 \mu \mathrm{m} ; B, 30 \mu \mathrm{m} ; C, 20$ $\mu \mathrm{m} ; D, 40 \mu \mathrm{m} ; E, 100 \mu \mathrm{m}$.

creases in cytosolic calcium levels of astrocytes (Fig. 8). In most experiments it was not possible to outline single processes on the basis of calcium imaging, and the extensive network of gap junctions interconnecting the end feet plastered at the vessel wall may couple the processes into a functional unit. Focal electrical stimulation triggered calcium waves, which often propagated along the vessel wall (Fig. 8).

Golgi noted as early as in 1885 that astrocytes frequently make contact with blood vessels. The existence of a blood-brain barrier was later recognized by the ability of the brain to exclude dyes injected into the general circulation (for review, see Wolburg and Risau, 1995). Numerous studies have since confirmed that the BBB excludes neuroactive substances and thereby maintains an environment optimal for synaptic transmission (Grant et al., 1998; Pardridge, 1999). Virtually all substances are excluded by the $\mathrm{BBB}$, with the exception of small lipophilic compounds and 
A
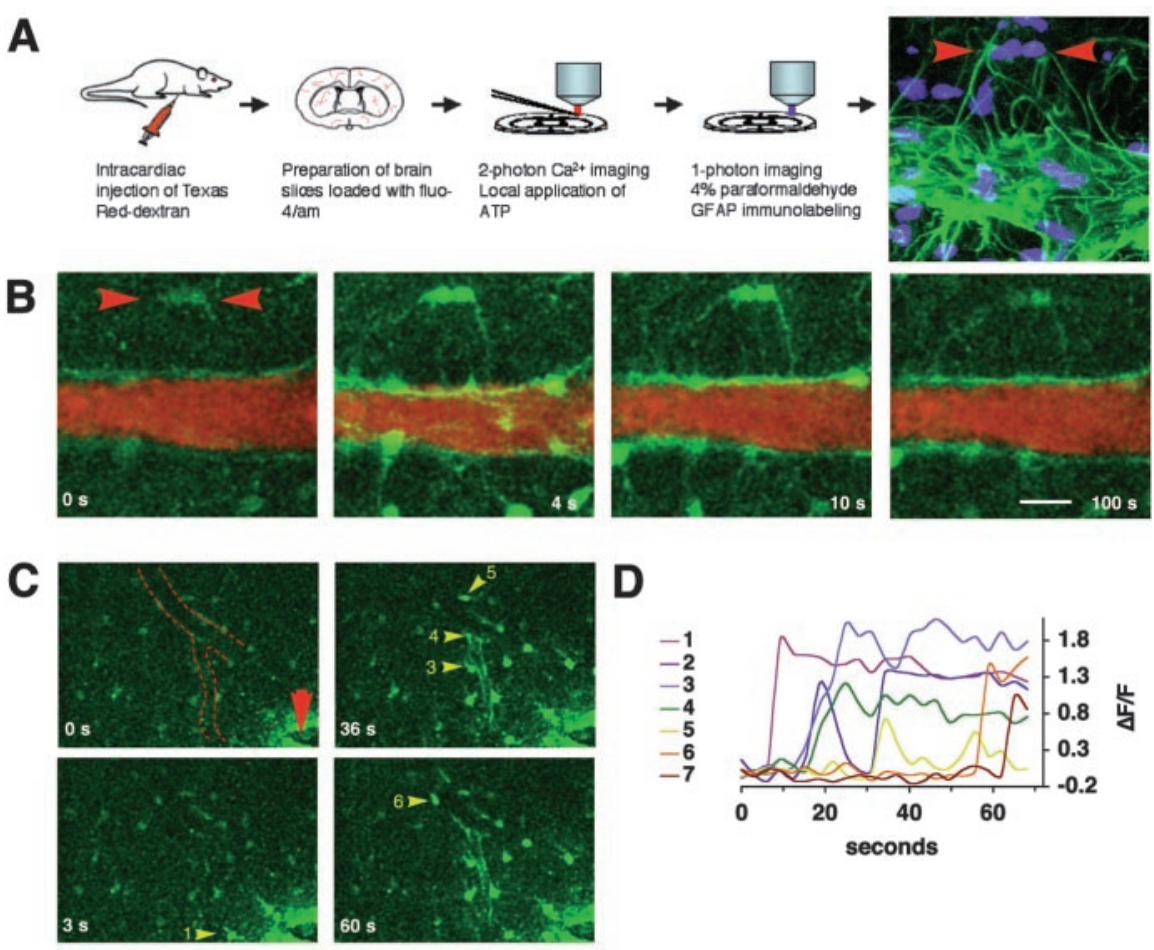

\section{D}
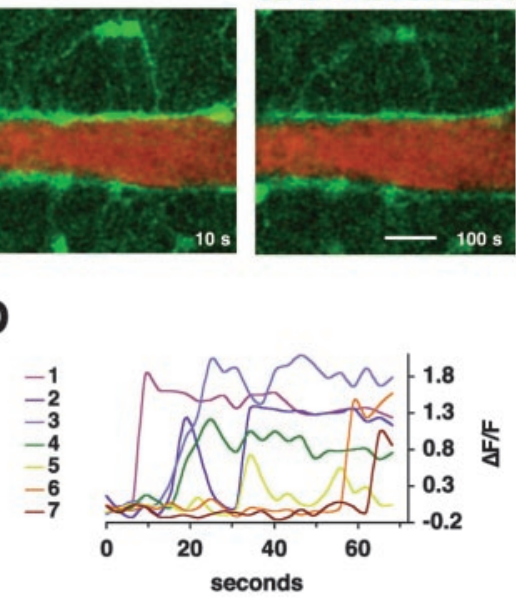
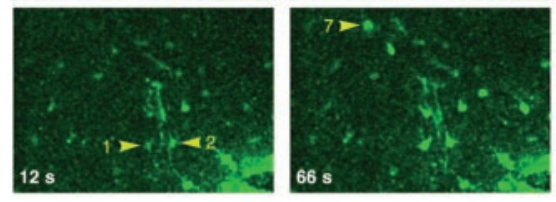

Figure 8. Purinergic receptor agonists mobilize cytosolic $\mathrm{Ca}^{2+}$ in astrocytic end-foot processes. $A$, Preparation of freshly prepared cortical brain slices (P15) used for multiphoton imaging. Last frame visualizes GFAP immunoreactivity (green) and nuclear staining (Sytox, blue) of the same slide used for $\mathrm{Ca}^{2+}$ imaging in $B$. Red arrowheads depict two GFAP-positive astrocytes with vascular processes that responded to ATP exposure. $B$, Increases in cytosolic $\mathrm{Ca}^{2+}$ evoked by local application of ATP (100 $\mu \mathrm{m})$ around the same vessel. The vessels were visualized by intracardial injection of Texas Red Dextran immediately before slide preparation. Fluo-4/AM is in green; Texas Red Dextran is in red. Red arrowheads depict the GFAP-positive astrocytes in $A$, last frame. C, Focal field stimulation ( 2 sec pulse, $100 \mathrm{~Hz}, 100 \mu \mathrm{A}$ ) evokes a $\mathrm{Ca}^{2+}$ wave that propagates along the vessel wall (red arrowhead indicates stimulation electrode; dotted line indicates medium-sized vessel). Astrocytes engaged in the $\mathrm{Ca}^{2+}$ wave are indicated by yellow arrowheads and numbered according the sequence that they engage in $\mathrm{Ca}^{2+}$ signaling. D, Relative increases in Fluo-4/AM signal $(\Delta F / F)$ of the astrocytes numbered in C. Scale bar: $A, B, 20 \mu \mathrm{m} ; C, 40 \mu \mathrm{m}$.

substrates for which transport systems exist (Drewes, 1999). The $\mathrm{BBB}$ is an endothelial barrier constructed by an extensive network of endothelial tight junctions (Kniesel and Wolburg, 2000). The role of astrocytes in the BBB is less defined, because they are physically separated from the endothelial cells by the basal lamina and do not contribute directly to the physical barrier. Several lines of evidence have suggested that the role of astrocytes is to provide appropriate environmental signals for the formation of endothelial tight junctions (Prat et al., 2001). Interestingly, a role for endothelial cells in inducing astrocyte differentiation has been demonstrated recently (Mi et al., 2001).

Several lines of work have previously implicated astrocytes in activity-dependent increases in local blood flow (Harder et al., 2002). Increases in extracellular potassium concentration are known to dilate cerebral arterioles, and the high potassium conductance of the astrocytic end-foot processes (Newman, 1986) has led to the hypothesis that astrocytic shunting of potassium in response to neuronal activity plays a role in local blood flow regulation (Paulson and Newman, 1987). An alternative possibility is that astrocytic calcium signaling evoked by intense neuronal firing mediates activity-induced increases in local blood flow.
Astrocytic calcium signaling is linked to release of prostaglandins, which are potent vasodilating agents (Kaley et al., 1985; Ballard and Achike, 1998; Bezzi et al., 1998). A recent study has supported the idea that glutamate released during synaptic transmission stimulates astrocytic calcium signaling resulting in a cyclooxygenase product-mediated vasodilation (Zonta et al., 2003). On the basis of our observation that the vascular foot processes of astrocytes expressed purinergic receptor and mobilized calcium in response to agonist exposure, it is critical for future studies to establish the role of purinergic signaling in local blood flow regulation (Anderson and Nedergaard, 2003).

We did not examine calcium responses of endothelial cells and pericytes in detail, but in general these cells responded weakly to purinergic receptor stimulation. Furthermore, P2Y(1), P2Y(2), and P2Y(4) receptors were not detected in either endothelial cells or pericytes (Figs. 5, 6). Astrocytes can transmit calcium signals to endothelial cells in cocultures by a signaling mechanism sensitive to purinergic receptor antagonists (Paemeleire and Leybaert, 2000). Also, cultured endothelial cells express $\mathrm{P} 2 \mathrm{Y}$ receptors and mobilize cytosolic calcium in response to purinergic agonist (Kunapuli and Daniel, 1998; Srinivas et al., 1998). Thus, the difference in $\mathrm{P} 2 \mathrm{Y}$ receptor expression can explain the seemingly opposite results obtained in vivo versus in vitro. It is important, however, to note that paracrine calcium signaling within the blood-brain barrier may be restricted by the basal lamina, which physically separates the endothelial cells from astrocytes. ATP is a short-range transmitter, rapidly degraded by extracellular ectonucleases (Burnstock, 2002), and it is unlikely that ATP can transmit calcium signals across the intact blood-brain barrier. During pathological conditions, alteration in the thickness or composition of the basal lamina may give rise to abnormal signaling pathways (del Zoppo and Hallenbeck, 2000). Pericytes migrate away from the vasculature within a few hours after brain injury, suggesting that new signaling loops can be established rapidly (Dore-Duffy et al., 2000). Also, the expression of purinergic receptors is dynamically regulated, and transient increases in expression of the P2Y(2) purinoceptor mRNA have been noted after exposure of cultured astrocytes to the cytokine IL-1 $\beta$ (John et al., 1999).

Astrocytes have long been recognized as the chief regulator of water homeostasis in brain (del Zoppo and Hallenbeck, 2000). We observed here that AQP-4 expression was highly polarized, and most immunoreactivity was present in astrocytic end feet facing the vessel wall. Freeze-fracture analysis has estimated that square arrays, composed of AQP-4, span as much as $50 \%$ of the surface area astrocytic end feet (Nielsen et al., 1997; Rash and Yasumura, 1999). Because brain endothelial cells do not express aquaporin channels, as observed by either immunostaining or 
freeze-fracture analysis, their water permeability is likely low (Verkman, 2002). The high expression of AQP-4 at the gliovascular interface is therefore unexplained, but it is interesting to note that cell volume regulation in several cell types has been linked to purinergic signaling (Wang et al., 1996; Feranchak et al., 2000). The marked paravascular expression of both AQP-4 and purinergic receptors therefore may suggest that brain water homeostasis is controlled by astrocytes at the level of the bloodbrain barrier.

Astrocytes are in situ highly polarized with a morphology that profoundly differs from their cultured counter-partners. We have here reexamined the structural organization of astrocytes in cortex and found that the key elements required for astrocytic calcium signaling, including purinergic receptors and gap junctions, were expressed intensively in the astrocytic end feet facing the vessel wall. Astrocytes are electrically nonexcitable cells that rely on purinergic receptors and gap junctions for long-distance communication. The extraordinary high expression of basic signaling elements in perivascular astrocytes suggests that astrocytic end feet are specialized to engage in active signaling processes.

\section{References}

Anderson C, Nedergaard M (2003) Astrocyte-mediated control of cerebral microcirculation. Trends Neurosci 26:340-344.

Araque A, Parpura V, Sanzgiri RP, Haydon PG (1998) Glutamatedependent astrocyte modulation of synaptic transmission between cultured hippocampal neurons. Eur J Neurosci 10:2129-2142.

Arcuino G, Lin JH, Takano T, Liu C, Jiang L, Gao Q, Kang J, Nedergaard M (2002) Intercellular calcium signaling mediated by point-source burst release of ATP. Proc Natl Acad Sci USA 99:9840-9845.

Ballard HJ, Achike FI (1998) Mechanism of action of prostaglandin E2 in the dog skeletal muscle circulation. Chin Med J (Engl) 111:945-950.

Bezzi P, Carmignoto G, Pasti L, Vesce S, Rossi D, Rizzini BL, Pozzan T, Volterra A (1998) Prostaglandins stimulate calcium-dependent glutamate release in astrocytes. Nature 391:281-285.

Burnstock G (2002) Purinergic signaling and vascular cell proliferation and death. Arterioscler Thromb Vasc Biol 22:364-373.

Bushong EA, Martone ME, Jones YZ, Ellisman MH (2002) Protoplasmic astrocytes in CA1 stratum radiatum occupy separate anatomical domains. J Neurosci 22:183-192.

Charles AC, Merrill JE, Dirksen ER, Sanderson MJ (1991) Intercellular signaling in glial cells: calcium waves and oscillations in response to mechanical stimulation and glutamate. Neuron 6:983-992.

Cornell-Bell AH, Finkbeiner SM, Cooper MS, Smith SJ (1990) Glutamate induces calcium waves in cultured astrocytes: long-range glial signaling. Science 247:470-473.

Cotrina ML, Lin JH, Alves-Rodrigues A, Liu S, Li J, Azmi-Ghadimi H, Kang J, Naus CC, Nedergaard M (1998) Connexins regulate calcium signaling by controlling ATP release. Proc Natl Acad Sci USA 95:15735-15740.

del Zoppo GJ, Hallenbeck JM (2000) Advances in the vascular pathophysiology of ischemic stroke. Thromb Res 98:73-81.

Dermietzel R, Hertberg EL, Kessler JA, Spray DC (1991) Gap junctions between cultured astrocytes: immunocytochemical, molecular, and electrophysiological analysis. J Neurosci 11:1421-1432.

Diaz-Flores L, Gutierrez R, Varela H, Rancel N, Valladares F (1991) Microvascular pericytes: a review of their morphological and functional characteristics. Histol Histopathol 6:269-286.

Dore-Duffy P, Owen C, Balabanov R, Murphy S, Beaumont T, Rafols JA (2000) Pericyte migration from the vascular wall in response to traumatic brain injury. Microvasc Res 60:55-69.

Drewes LR (1999) What is the blood-brain barrier? A molecular perspective. Cerebral vascular biology. Adv Exp Med Biol 474:111-122.

Duijvestijn AM, van Goor H, Klatter F, Majoor GD, van Bussel E, van Breda Vriesman PJ (1992) Antibodies defining rat endothelial cells: RECA-1, a pan-endothelial cell-specific monoclonal antibody. Lab Invest 66:459-466.

Feranchak AP, Fitz JG, Roman RM (2000) Volume-sensitive purinergic signaling in human hepatocytes. J Hepatol 33:174-182.

Gabriels JE, Paul DL (1998) Connexin43 is highly localized to sites of disturbed flow in rat aortic endothelium but connexin 37 and connexin 40 are more uniformly distributed. Circ Res 83:636-643.
Giaume C, Fromaget C, el Aoumari A, Cordier J, Glowinski J, Gros D (1991) Gap junctions in cultured astrocytes: single-channel currents and characterization of channel-forming protein. Neuron 6:133-143.

Grafstein B, Liu S, Cotrina ML, Goldman SA, Nedergaard M (2000) Meningeal cells can communicate with astrocytes by calcium signaling. Ann Neurol 47:18-25.

Grant GA, Abbott NJ, Janigro D (1998) Understanding the physiology of the blood-brain barrier: in vitro models. News Physiol Sci 13:287-293.

Guthrie PB, Knappenberger J, Segal M, Bennett MV, Charles AC, Kater SB (1999) ATP released from astrocytes mediates glial calcium waves. J Neurosci 19:520-528.

Harder DR, Zhang C, Gebremedhin D (2002) Astrocytes function in matching blood flow to metabolic activity. News Physiol Sci 17:27-31.

Haydon PG (2000) Neuroglial networks: neurons and glia talk to each other. Curr Biol 10:R712-714.

Hong T, Hill CE (1998) Restricted expression of the gap junctional protein connexin 43 in the arterial system of the rat. J Anat 192:583-593.

Jimenez AI, Castro E, Communi D, Boeynaems JM, Delicado EG, Miras-Portugal MT (2000) Coexpression of several types of metabotropic nucleotide receptors in single cerebellar astrocytes. J Neurochem 75:2071-2079.

John GR, Scemes E, Suadicani SO, Liu JS, Charles PC, Lee SC, Spray DC, Brosnan CF (1999) IL-1beta differentially regulates calcium wave propagation between primary human fetal astrocytes via pathways involving P2 receptors and gap junction channels. Proc Natl Acad Sci USA 96:11613-11618.

Kaley G, Hintze TH, Panzenbeck M, Messina EJ (1985) Role of prostaglandins in microcirculatory function. Adv Prostaglandin Thromb Leukot Res 13:27-35.

Kang J, Nedergaard M (2000) Imaging astrocytes in acute brain slices. Cold Spring Harbor, NY: Cold Spring Harbor Laboratory.

Kang J, Jiang L, Goldman SA, Nedergaard M (1998) Astrocyte-mediated potentiation of inhibitory synaptic transmission. Nat Neurosci $1: 683-692$.

Kniesel U, Wolburg H (2000) Tight junctions of the blood-brain barrier. Cell Mol Neurobiol 20:57-76.

Kunapuli SP, Daniel JL (1998) P2 receptor subtypes in the cardiovascular system. Biochem J 336:513-523.

Mi H, Haeberle H, Barres BA (2001) Induction of astrocyte differentiation by endothelial cells. J Neurosci 21:1538-1547.

Morris DC, Zhang Z, Davies K, Fenstermacher J, Chopp M (1999) High resolution quantitation of microvascular plasma perfusion in nonischemic and ischemic rat brain by laser-scanning confocal microscopy Brain Res Brain Res Protoc 4:185-191.

Nakano M, Atobe Y, Goris RC, Yazama F, Ono M, Sawada H, Kadota T, Funakoshi K, Kishida R (2000) Ultrastructure of the capillary pericytes and the expression of smooth muscle alpha-actin and desmin in the snake infrared sensory organs. Anat Rec 260:299-307.

Nedergaard M (1994) Direct signaling from astrocytes to neurons in cultures of mammalian brain cells. Science 263:1768-1771.

Newman EA (1986) High potassium conductance in astrocyte endfeet. Science 233:453-454.

Newman EA, Zahs KR (1998) Modulation of neuronal activity by glial cells in the retina. J Neurosci 18:4022-4028.

Nielsen S, Nagelhus EA, Amiry-Moghaddam M, Bourque C, Agre P, Ottersen OP (1997) Specialized membrane domains for water transport in glial cells: high-resolution immunogold cytochemistry of aquaporin-4 in rat brain. J Neurosci 17:171-180.

Paemeleire K, Leybaert L (2000) ATP-dependent astrocyte-endothelial calcium signaling following mechanical damage to a single astrocyte in astrocyte-endothelial co-cultures. J Neurotrauma 17:345-358.

Pardridge WM (1999) Blood-brain barrier biology and methodology. J Neurovirol 5:556-569.

Parpura V, Basarsky TA, Liu F, Jeftinija K, Jeftinija S, Haydon PG (1994) Glutamate-mediated astrocyte-neuron signaling. Nature 369:744-747.

Paulson OB, Newman EA (1987) Does the release of potassium from astrocyte endfeet regulate cerebral blood flow? Science 237:896-898.

Prat A, Biernacki K, Wosik K, Antel JP (2001) Glial cell influence on the human blood-brain barrier. Glia 36:145-155.

Rash JE, Yasumura T (1999) Direct immunogold labeling of connexins and aquaporin-4 in freeze-fracture replicas of liver, brain, and spinal cord: factors limiting quantitative analysis. Cell Tissue Res 296:307-321. 
Robitaille R (1998) Modulation of synaptic efficacy and synaptic depression by glial cells at the frog neuromuscular junction. Neuron 21:847-855.

Simpson IA, Vannucci SJ, DeJoseph MR, Hawkins RA (2001) Glucose transporter asymmetries in the bovine blood-brain barrier. J Biol Chem 276:12725-12729.

Smith SJ (1992) Do astrocytes process neural information? Prog Brain Res 94:119-136.

Srinivas SP, Yeh JC, Ong A, Bonanno JA (1998) $\mathrm{Ca}^{2+}$ mobilization in bovine corneal endothelial cells by P2 purinergic receptors. Curr Eye Res 17:994-1004

Verkman AS (2002) Aquaporin water channels and endothelial cell function. J Anat 200:617-627.

Wang Y, Roman R, Lidofsky SD, Fitz JG (1996) Autocrine signaling through ATP release represents a novel mechanism for cell volume regulation. Proc Natl Acad Sci USA 93:12020-12025.

Wolburg H, Risau W (1995) Formation of the blood-brain barrier. In: Neuroglia (Kettenmann H, Ransom B, eds), pp 763-776. New York: Oxford UP.
Yamamoto T, Ochalski A, Hertzberg EL, Nagy JI (1990) On the organization of astrocytic gap junctions in rat brain as suggested by LM and EM immunohistochemistry of connexin43 expression. J Comp Neurol 302:853-883.

Zahs KR, Newman EA (1997) Asymmetric gap junctional coupling between glial cells in the rat retina. Glia 20:10-22.

Zhang ZG, Bower L, Zhang RL, Chen S, Windham JP, Chopp M (1999) Three-dimensional measurement of cerebral microvascular plasma perfusion, glial fibrillary acidic protein and microtubule associated protein-2 immunoreactivity after embolic stroke in rats: a double fluorescent labeled laser-scanning confocal microscopic study. Brain Res 844:55-66.

Zhu Y, Kimelberg HK (2001) Developmental expression of metabotropic $\mathrm{P} 2 \mathrm{Y}(1)$ and $\mathrm{P} 2 \mathrm{Y}(2)$ receptors in freshly isolated astrocytes from rat hippocampus. J Neurochem 77:530-541.

Zonta M, Angulo MC, Gobbo S, Rosengarten B, Hossmann KA, Pozzan T, Carmignoto G (2003) Neuron-to-astrocyte signaling is central to the dynamic control of brain microcirculation. Nat Neurosci 6:43-50. 